\title{
BMJ Open Interactions between physicians and the pharmaceutical industry generally and sales representatives specifically and their association with physicians' attitudes and prescribing habits: a systematic review
}

\author{
Freek Fickweiler, Ward Fickweiler, Ewout Urbach
}

To cite: Fickweiler $F$, Fickweiler W, Urbach E. Interactions between physicians and the pharmaceutical industry generally and sales representatives specifically and their association with physicians' attitudes and prescribing habits: a systematic review. BMJ Open 2017;7:e016408. doi:10.1136/ bmjopen-2017-016408

- Prepublication history and additional material for this paper are available online. To view please visit the journal (http:// dx.doi.org/10.1136/bmjopen2017-016408).

Received 18 February 2017 Revised 20 July 2017 Accepted 2 August 2017

\section{(a) CrossMark}

Crowd for Cure, Groningen, Groningen, The Netherlands

Correspondence to

Freek Fickweiler;

freek@crowdforcure.com

\section{ABSTRACT}

Objectives The objective of this review is to explore interactions between physicians and the pharmaceutical industry including sales representatives and their impact on physicians' attitude and prescribing habits.

Data sources PubMed, Embase, Cochrane Library and Google scholar electronic databases were searched from 1992 to August 2016 using free-text words and medical subject headings relevant to the topic.

Study selection Studies included cross-sectional studies, cohort studies, randomised trials and survey designs. Studies with narrative reviews, case reports, opinion polls and letters to the editor were excluded from data synthesis.

Data extraction Two reviewers independently extracted the data. Data on study design, study year, country, participant characteristics, setting and number of participants were collected.

Data synthesis Pharmaceutical industry and pharmaceutical sales representative (PSR) interactions influence physicians' attitudes and their prescribing behaviour and increase the number of formulary addition requests for the company's drug.

Conclusion Physician-pharmaceutical industry and its sales representative's interactions and acceptance of gifts from the company's PSRs have been found to affect physicians' prescribing behaviour and are likely to contribute to irrational prescribing of the company's drug. Therefore, intervention in the form of policy implementation and education about the implications of these interactions is needed.

\section{INTRODUCTION}

The relationship between physicians and the pharmaceutical industry has evoked heated debate for many decades. ${ }^{1}$ In 2012, the pharmaceutical industry spent $\$ 89.5$ billion on physician-pharmaceutical sales representative (PSR) interactions that accounted for $60 \%$ of the global sales and marketing spending. ${ }^{2-8}$ Previous reports have demonstrated that
Strengths and limitations of this study

Large up-to-date systematic review of studies exploring the impact of pharmaceutical industry representative interactions on physicians.

- This systematic review used the recommendations outlined in the Cochrane Handbook for conducting systematic reviews and the Grading of Recommendations Assessment, Development and Evaluation (GRADE) methodology to assess the quality of the evidence by outcome.

- PubMed, Embase, Cochrane Library and Google Scholar electronic databases were searched from 1992, as well as grey literature.

- Most studies identified were observational and of varying methodological design.

- Some studies did not provide evidence for the significance of their findings.

PSRs may influence prescribing behaviour. ${ }^{9-16}$ However, the evidence determining whether pharmaceutical industry and PSRs interactions influence physicians is divided and contradictory. Studies have indicated that physicians may be unable to distinguish between promotional information and scientific evidence. ${ }^{17} 18$ Physicians, however, believe their colleagues are more susceptible to pharmaceutical industry marketing strategies than themselves. ${ }^{19-22}$ The majority of the physicians do not believe that they are affected by pharmaceutical industry and PSR interactions. Most medical and governmental institutions have installed guidelines and self-regulatory and legislative checks to regulate the relationship between physicians and the pharmaceutical industry and its representatives. ${ }^{5} 151623-26$ However, while administrative proposals for deregulatory reforms 


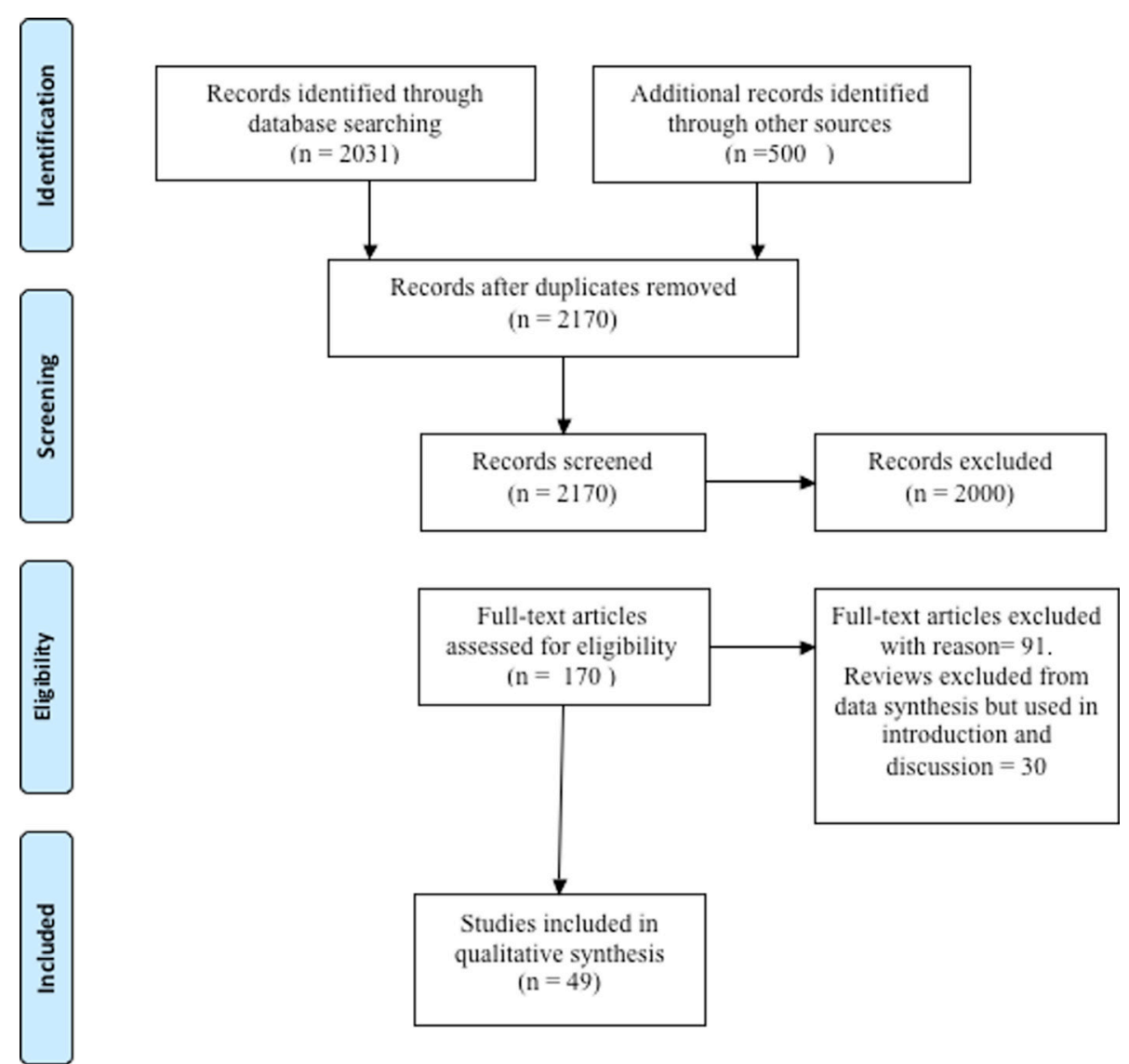

Figure 1 PRISMA flow diagram showing search strategy and included studies. PRISMA, Preferred Reporting Items for Systematic Reviews and Meta-Analyses.

that would remove some governmental authority over the industry are increasing, scientific evidence rigorously examining the extent of interactions between physicians and pharmaceutical industry and it PSRs is needed. This review evaluates critically and systemically the evidence on the impact of pharmaceutical industry and PSR interactions on physicians.

\section{METHODOLOGY \\ Protocol}

We followed a detailed methodology that we described in our review protocol, which is available on request to the corresponding author. Two independent reviewers assessed selected articles as per inclusion/exclusion criteria, shortlisted them for writing the review and crosschecked their decisions about inclusion/exclusion with each other. The review followed the Preferred Reporting Items for Systematic Reviews and Meta-Analyses guidelines (supplementary appendix 1).

\section{Eligibility criteria}

The eligibility criteria were:

- types of studies: observational study design, such as cross-sectional studies and cohort studies, but also (non-) randomised trials and survey designs comparing at least one facet that are mentioned below on the impact on behaviour and attitude;
- types of participants: physicians, pharmaceutical representatives and physicians in training/residents;

- types of exposure: any type of interaction between physicians and the pharmaceutical industry where there is direct interaction with the physician, such as meeting with drug representatives, participating in pharmaceutical-sponsored Continuing Medical Education (CME) events, receiving travel funding, free drug samples, industry-provided meals, gifts and presentations of industry-related information;

- types of outcome: knowledge, beliefs and/or attitudes of physicians regarding physician-industry interactions and (prescribing) behaviour of physicians;

- type of control: no interaction.

- Exclusion criteria were: qualitative, ecological, econometric studies, editorials, letters to the editor, studies on other health professionals (eg, nurses and medical students), small samples sizes, studies assessing indirect interactions and research funding.

We did not exclude studies based on risk of bias. We took risk of bias into account when grading the quality of evidence using GRADE approach.

\section{Search strategy}

The search strategy included PubMed, Embase, Cochrane Library and Google Scholar electronic databases (January 1992 to August 2016). Databases were not searched 
before 1992, as these studies were already investigated in an earlier review. ${ }^{27}$ The search combined terms for physicians and pharmaceutical and included both free-text words and medical subject heading relevant to the topic. We did not use a search filter. The online supplementary information file provides the full details for one database. Additional search strategies included a search of the grey literature (theses and dissertations). Also, we reviewed the references lists of included and relevant papers. ${ }^{27-29}$

\section{Assessment of risk of bias in included studies}

Two reviewers assessed in duplicate and independently the risk of bias in each eligible study. Disagreements were resolved by discussion or adjudication by a third reviewer. We used the recommendations outlined in the Cochrane Handbook to assess the risk of bias in randomised studies. We graded each potential source of bias and rated the studies as high, low or unclear risk of bias.

\section{Data analysis and synthesis}

The information extracted from the selected studies included type of study, study design, type of pharmaceutical industry and PSR interaction and type of outcome. We did not conduct a meta-analysis due to the heterogeneity of study design, types of interventions, outcomes assessed and outcome measures used. Instead, we summarised the data narratively. We assessed the quality of evidence by outcome using the GRADE methodology. ${ }^{30}$

\section{RESULTS}

We independently screened the titles and abstracts of the 2170 identified records for potential eligibility. Out of 2170, the full text of 49 eligible citations that matched the inclusion criteria were retrieved and used for qualitative assessment during the writing of the review (figure 1, table 1).

\section{Characteristics of included studies}

The identified studies were published between 1992 and August 2016. Most of the studies included were cross-sec-

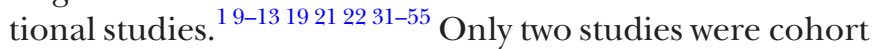
studies, $^{5657}$ three were randomised trials ${ }^{58-60}$ and one study was a case-control study. ${ }^{61}$

\section{Extent of interactions between physicians and the pharmaceutical industry}

We found that PSR interactions are a regular feature in the daily lives of physicians across the world. ${ }^{9-11} 134250$ Most of the attending physicians and residents have at least one interaction with industry representatives per month. ${ }^{1021223642}$ The frequency of interactions or gifts offered and accepted varies with private versus public hospital setting and the position of the physicians in the medical hierarchy. ${ }^{10} 1331384243505862$ Junior residents received twice as much free drug samples from PSR interactions than senior residents. ${ }^{10}$ PSR interactions were significantly higher at the beginning of residency. ${ }^{13}$ The majority of programme directors of internal medicine residencies in the USA allowed PSRs to meet with residents during working hours and permitted PSR sponsorship of conferences. ${ }^{40}$ Attending physicians and physician specialists had more PSR interactions and received higher numbers of medical samples and promotional material than residents. ${ }^{9}{ }^{42}$ Participants working in private practice alone or in both sectors were more likely to receive gifts than physicians working in the public sector. ${ }^{38} 4250$ Most common gifts received were medical samples, ${ }^{9} 21223136374263$ promotional material ${ }^{9} 3442$ invitations for dinners, ${ }^{9}$ invitations for CMEs, ${ }^{22}{ }^{34}$ scientific journals $^{34}$ and free lunches. ${ }^{21} 37$

\section{Perspectives of physicians towards PSR interactions}

We found that physicians have a positive attitude towards

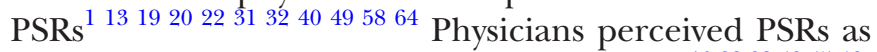
important sources of education and funding, ${ }^{10} 2232434546$; while some studies reporting sceptical attitudes about the contribution of PSRs towards teaching and education. $^{21} 36394049$ Conference registration fees, informational luncheons, sponsorship of departmental journal clubs, anatomical models and free drug samples were considered as appropriate gifts. ${ }^{19} 395158$ Most of the physicians considered pharmaceutical information provided by PSRs, industry-sponsored conferences and CME events as important instruments for enhancing their scientific knowledge. $^{22} 324546$ Compared with senior residents, significantly more junior residents felt that pharmaceutical representatives have a valuable teaching role. ${ }^{10}$

Most studies found that physicians do not believe that PSRinteractions impact their prescribing behavoir, ${ }^{19-136566}$ while other studies found that there was some extent of influence. ${ }^{21} 223436373943$ In addition, physicians considered their colleagues more susceptible than themselves to PSR marketing strategies. ${ }^{120} 213743$ There was a strong correlation between the amount of gifts and the belief that PSR interactions did not influence their prescribing behaviour. $^{10}$

\section{Gifts}

We found that better scores on knowledge and attitudes were significantly associated with fewer interactions with representatives and their gifts. ${ }^{19}$ Conference registration fees, informational luncheons, sponsorship of departmental journal clubs, anatomical models and free drug samples were considered as appropriate gifts ${ }^{19} 374752$ Most of the physicians considered themselves immune to the influence of gifts. ${ }^{1} 10323335395358$ Most common gifts received were medical samples, ${ }^{9} 212231363742-4447$ promotional material, ${ }^{9} 344267$ invitations for dinners ${ }^{9}$ and scientific journals. ${ }^{34}$

\section{Drug samples}

Most of the physicians who accepted drug samples had a positive attitude towards the pharmaceutical representatives. ${ }^{9} 21223136374243$ Accepting samples lead to higher branded drug prescription rather than generic prescribing. ${ }^{22} 47$ 


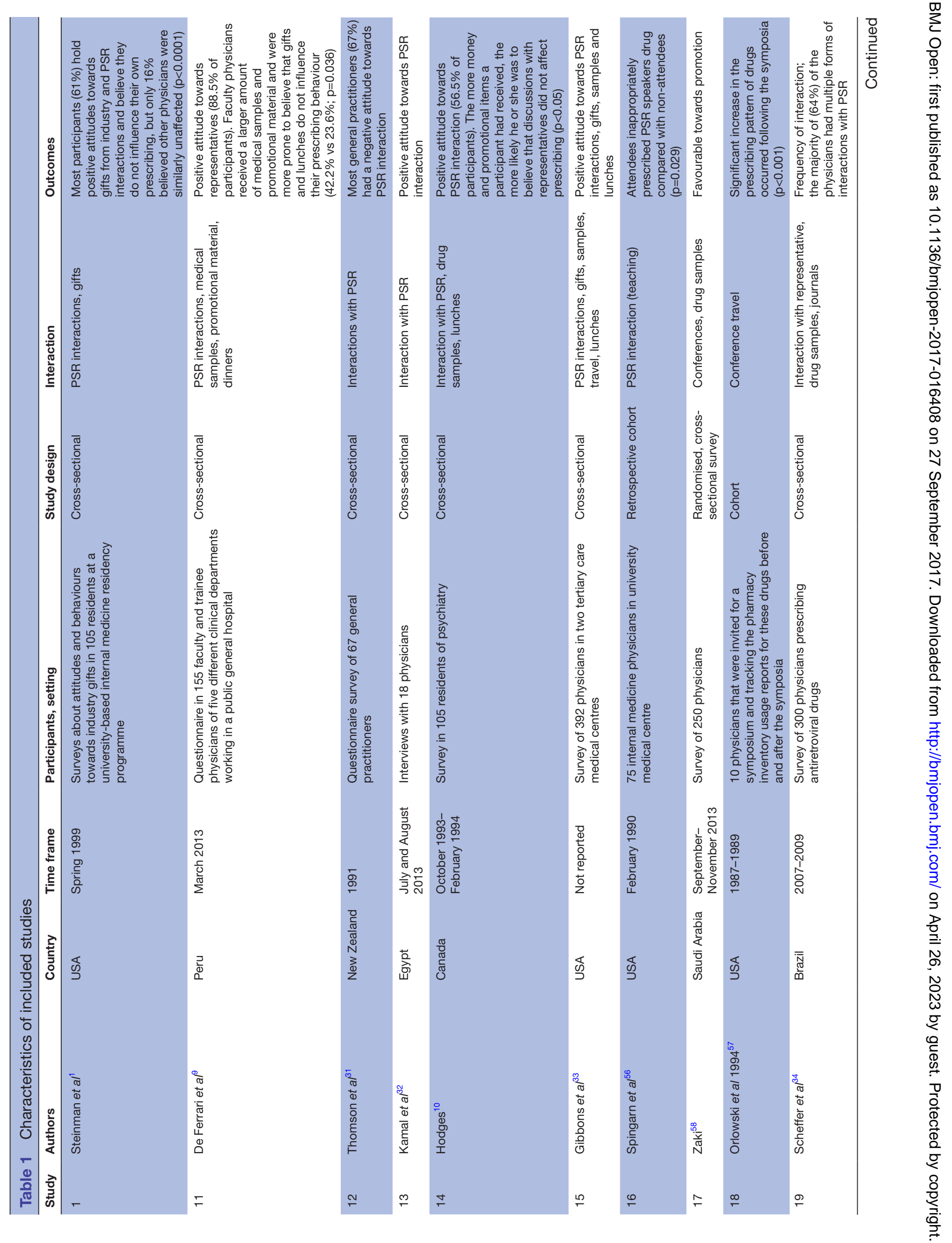



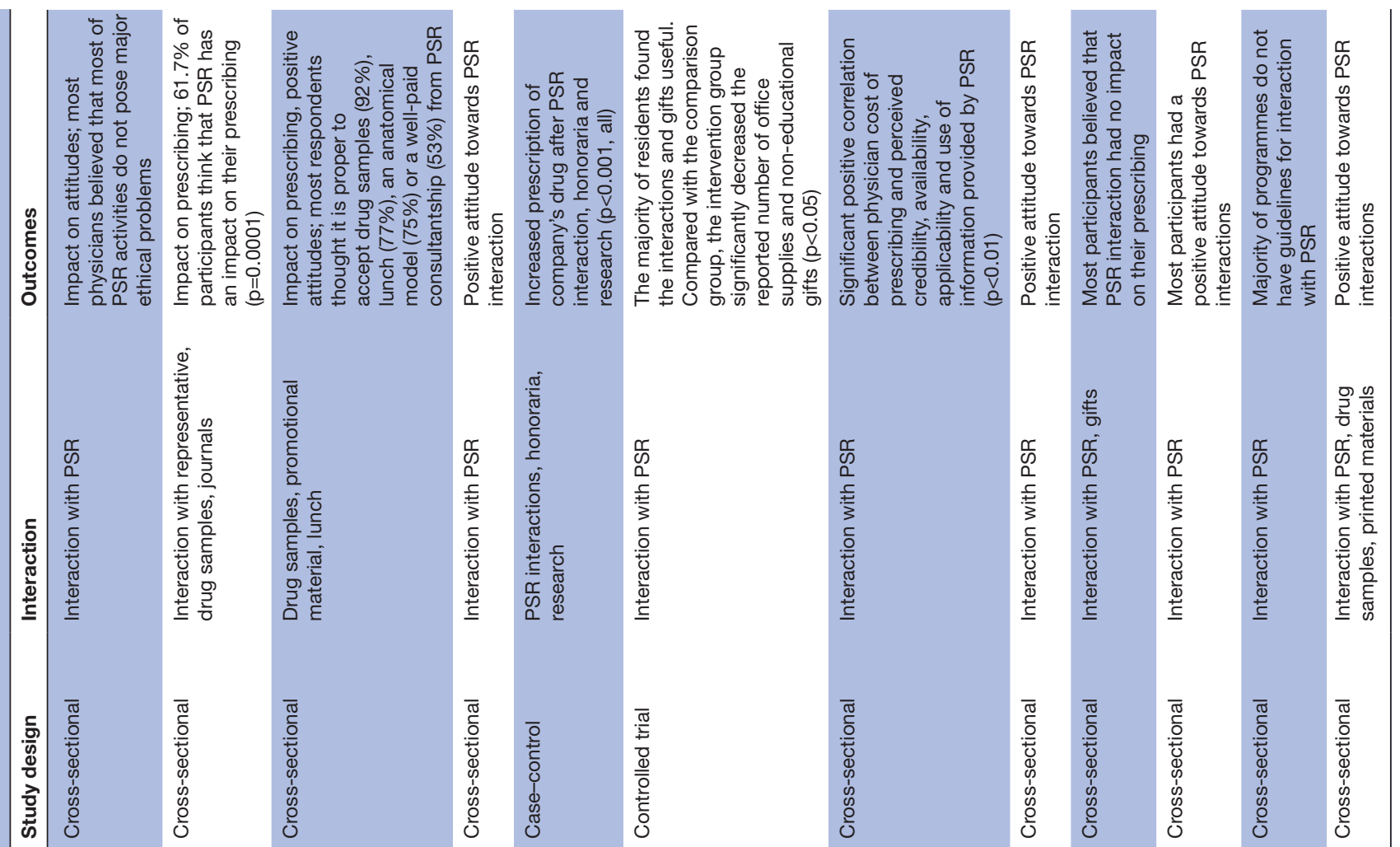

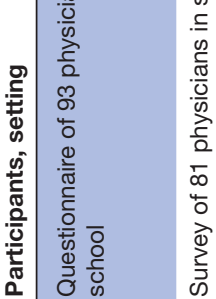
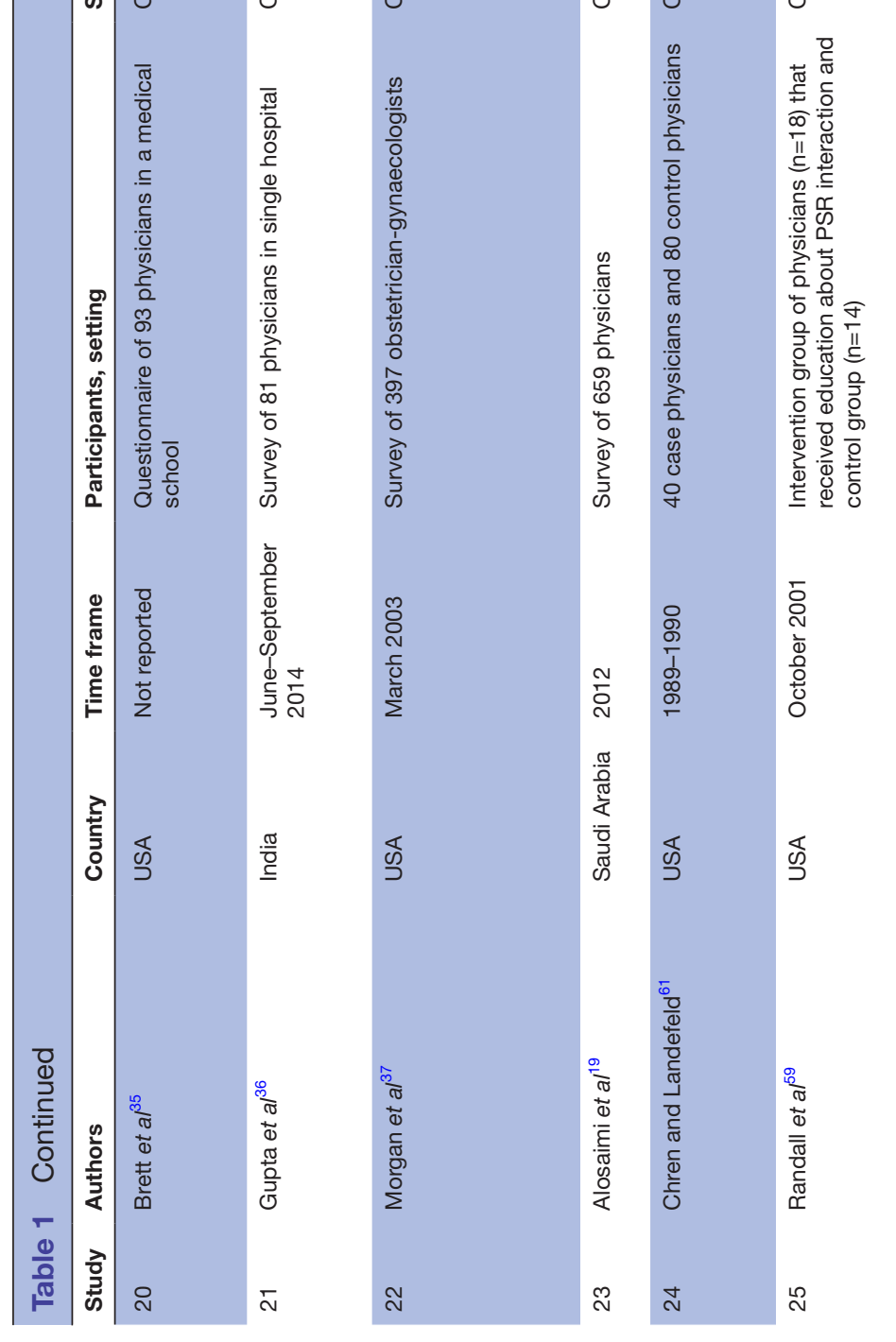


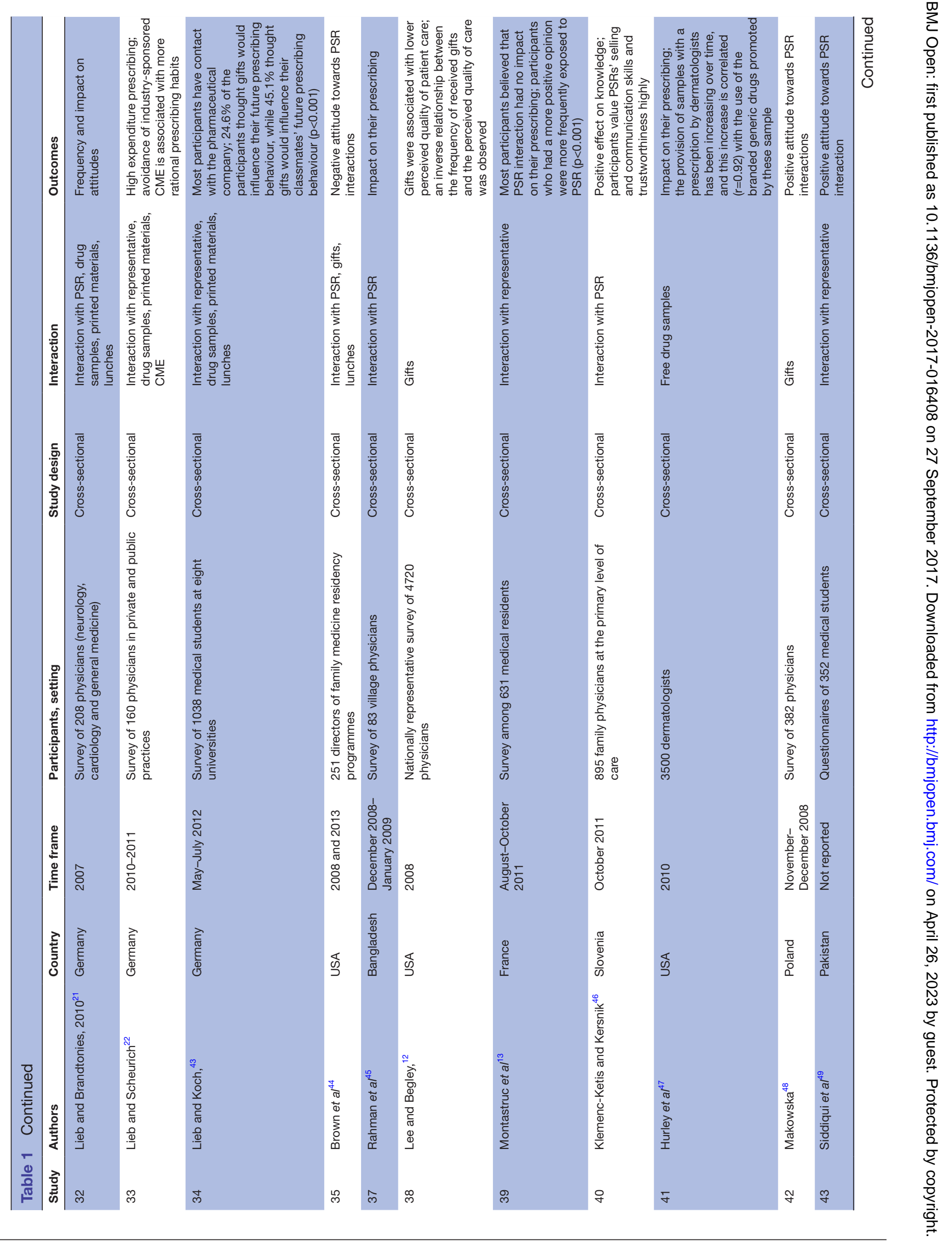




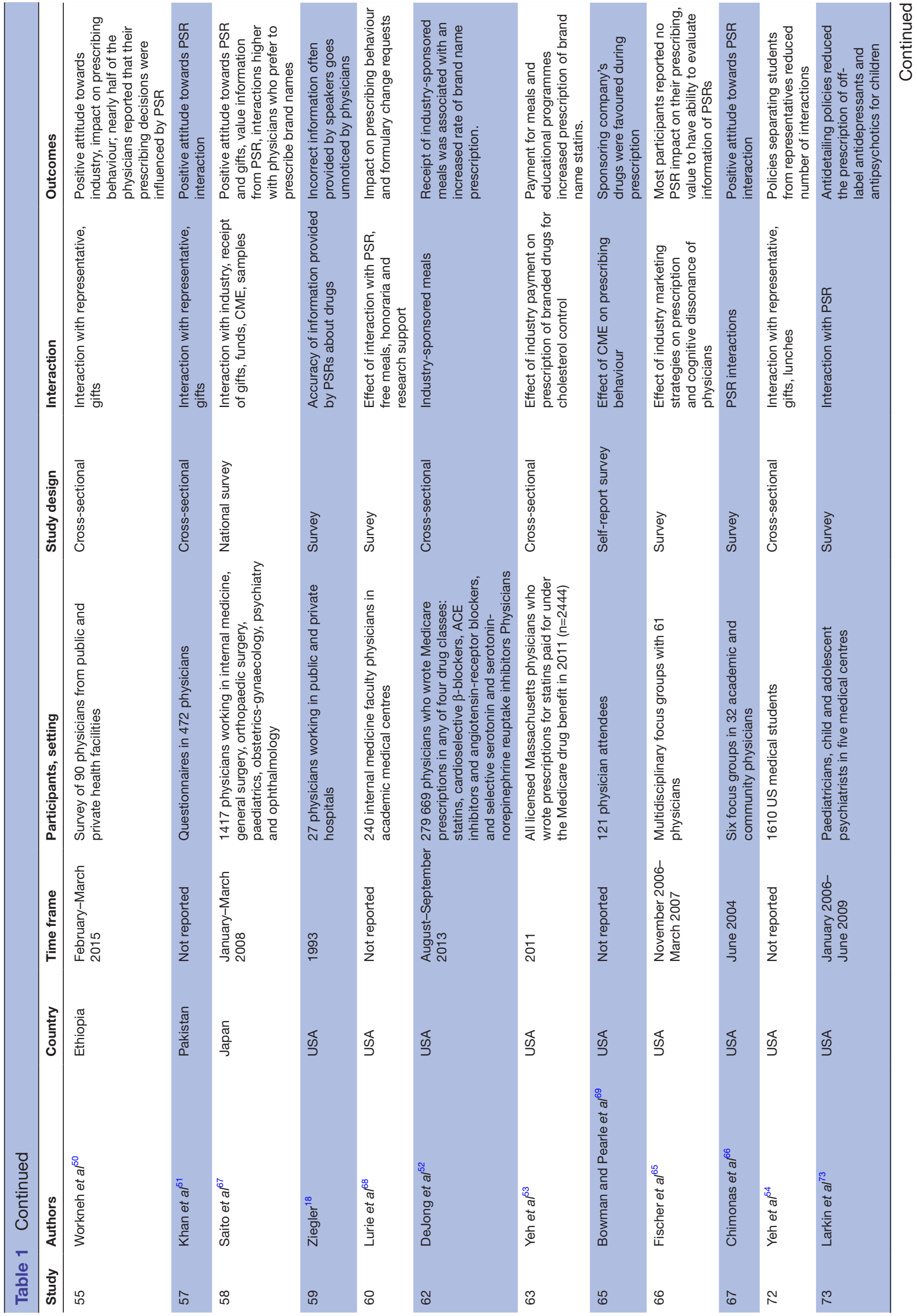




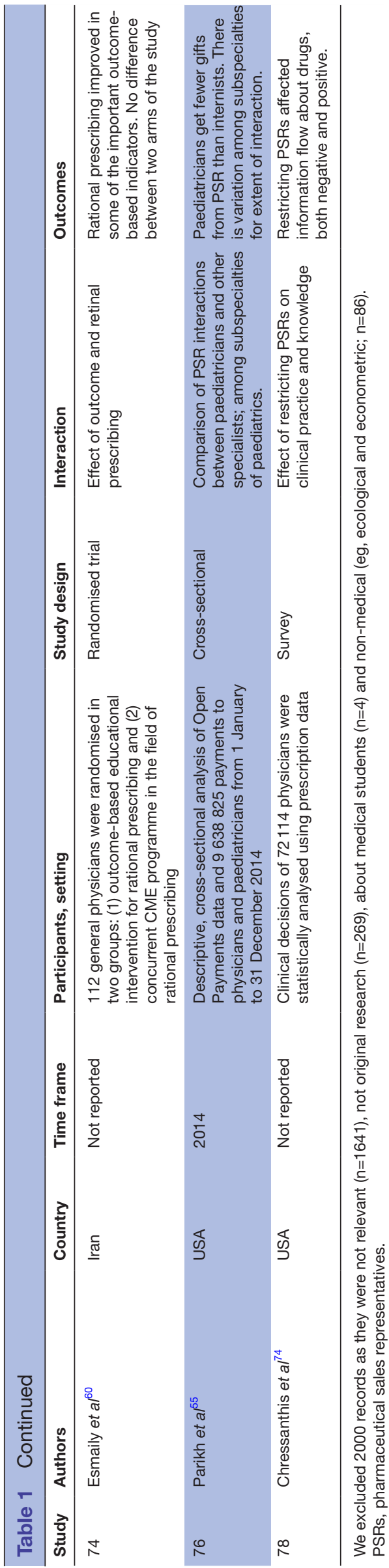

\section{Pharmaceutical representative speakers}

Sponsored lectures/symposia of pharmaceutical companies influenced behaviour of the attendees leading to the attendees prescribing more drugs from the sponsoring companies without sufficient evidence supporting superiority of those drugs. ${ }^{567}$ The majority of attending physicians failed to identify inaccurate information about the company drug. ${ }^{18}$

\section{Honoraria and research funding}

Physicians who received money to attend pharmaceutical symposia or to perform research requested formulary addition of the company's drug more often than other physicians. This association was independent of many confounding factors ${ }^{61}$ (table 2). Brief encounters with PSRs and receipt of honoraria or research support were predictors of faculty requested change in hospital formulary. ${ }^{68}$

\section{Conference travel}

Pharmaceutical company-sponsored conference travels to touristic locations have quantifiable impact on the prescribing rational of attendees. A significant increase (three times) in the prescribing rate of two company drugs was observed after the physicians attended a company-sponsored symposium with all their expenses covered. Despite this significant difference in the prescribing patterns, physicians insisted there was no impact on their prescribing behaviour. ${ }^{57}$

\section{Industry-paid lunches}

Most physicians received invitations for dinners ${ }^{9}$ and free lunches. ${ }^{10} 213543$ Clerks, interns and junior residents attended more company-sponsored lunches than senior residents. ${ }^{10}$ Pharmaceutical companies also sponsored departmental lunches during journal clubs. ${ }^{39}$ There was no significant association between attending industry-paid lunches ${ }^{37}$ and dinners ${ }^{9}$ and formulary request for that company's drug (table 2).

\section{CME sponsorship}

Physicians who attended company-sponsored CME events had more positive attitudes towards and inclination to prescribe the branded drugs. ${ }^{28} 34436769-71$ We found that physicians who refused CME sponsorship were seen to prescribe higher proportion of generics and lower expenditure medicines when compared with physicians who attended CMEs. $^{22}$

\section{DISCUSSION}

We report that there is widespread interaction between the pharmaceutical industry and physicians. ${ }^{9-11} 134250$ Interactions are in the form of personal communications, free gifts such as drug samples, sponsored meals, sponsored conference travel, funding for research and CMEs and honoraria. ${ }^{921} 22313642$ The frequency of these interactions is comparable between residents and physicians. ${ }^{102122} 3642$ However, the amount and type of gifts vary with the position 


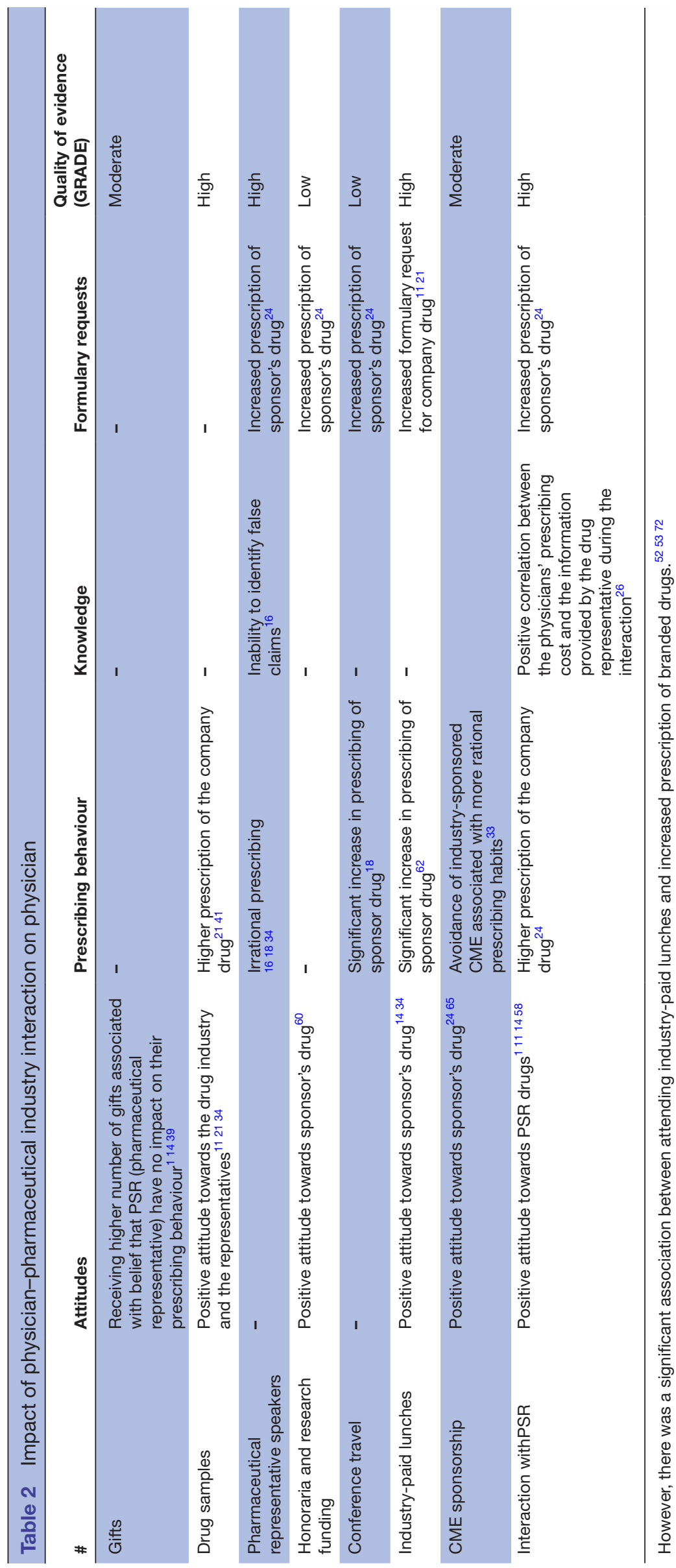


of the physician in medical hierarchy, specialisation and location of practice. ${ }^{101331384243505862}$ In general, trainees (residents and interns) are treated with more drug samples, stationery items and free meals than senior physicians. ${ }^{13}$ Senior physicians usually avail of sponsored conferences/ trips, research funding, honoraria and CME events. The extent of these interactions varies with academic versus non-academic institutions: non-academic hospitals record more interactions than others. ${ }^{31} 38425055$ The majority of the physicians do not believe that they are affected by PSR interactions. ${ }^{1} 10323335374359$ However, a sizeable percentage in various surveys responded in the affirmative when asked whether they thought that their peers are vulnerable. ${ }^{10213743}$

\section{Policies and educational intervention}

The relationship of physicians with patients is of a fiduciary nature. Hence, activities that might affect that relationship by altering physicians' clinical behaviour are not acceptable. Physician-pharmaceutical industry and PSR interactions may put the trust of patients in physicians at risk. Interaction with pharmaceutical industry and PSRs begins early in the physicians' career. Trainees are exposed to pharmaceutical industry marketing and promotional techniques from the initial years of their medical education, which impact their prescribing behaviour in future. Overall, trainees, that is, residents and interns, are more vulnerable to pharmaceutical industry and PSR interactions than senior physicians ${ }^{114162}$ Physicians are susceptible to pharmaceutical industry and PSR interactions, which influences their clinical decision making leading to greater prescriptions of branded drugs over low-cost generic medicines and increasing healthcare costs. ${ }^{22} 47525372$ Therefore, there is need to institute and implement stringent policies curtailing physicianpharmaceutical industry and PSR relationships, as well as educational programmes to increase awareness. Previous reports have indicated that implementing policies and conducting educational programmes are effective in increasing awareness of physician's attitudes towards pharmaceutical industry and PSR interactions. ${ }^{54} 5960$ 73-83

\section{Strengths and limitations of the study}

A major strength of this study is that it is a large, up-to-date systematic review of studies exploring the effects of physician and pharmaceutical industry representative interactions and residents in different settings (eg, academic and primary care). Another strength of this study is the use of Cochrane and GRADE methodologies for conducting a review and assessing the quality of the studies. Moreover, we performed an extensive search in three databases and the grey literature. Some of the limitations of this review are related to the included studies, as some did not provide evidence for the significance of their findings or had varying study designs and outcomes, which made it impossible to conduct a meta-analysis. Also, the included studies were subject to risk of bias related to the lack of validity of outcome measurement and inadequate handling of significant potential confounders.

\section{Future implications}

Pharmaceutical industry and PSR interactions compromise the objectivity of the physicians. Educating physicians and increasing regulation of pharmaceutical industry and PSR interactions may lower the likelihood of prescribing new non-superior industry drugs and irrational prescription behaviour. Further studies are required to evaluate the impact of pharmaceutical industry and PSR interactions on physicians over time and the benefits of various intervention-based education programmes on the clinical and ethical behaviour of the physicians.

Contributors All authors have contributed equally and have substantial contributions to the conception or design of the work: FF for the acquisition, analysis and interpretation of data for the work and drafting the work, EU and WF for revising it critically for important intellectual content and all authors contributed to final approval of the version to be published and agreed to be accountable for all aspects of the work in ensuring that questions related to the accuracy or integrity of any part of the work are appropriately investigated and resolved.

Competing interests None declared.

Provenance and peer review Not commissioned; externally peer reviewed.

Data sharing statement Any data relevant to a published article will be made available alongside the article when published.

Open Access This is an Open Access article distributed in accordance with the terms of the Creative Commons Attribution (CC BY 4.0) license, which permits others to distribute, remix, adapt and build upon this work, for commercial use, provided the original work is properly cited. See: http://creativecommons.org/ licenses/by/4.0/

(C) Article author(s) (or their employer(s) unless otherwise stated in the text of the article) 2017. All rights reserved. No commercial use is permitted unless otherwise expressly granted.

\section{REFERENCES}

1. Steinman MA, Shlipak MG, McPhee SJ. Of principles and pens: attitudes and practices of medicine housestaff toward pharmaceutical industry promotions. Am J Med 2001;110:551-7.

2. Wazana A. Physicians and the Pharmaceutical Industry. JAMA 2000;283:373.

3. Wolfe SM. Why do american drug companies spend more than $\$ 12$ billion a year pushing drugs? Is it education or promotion? J Gen Intern Med 1996;11:637-9.

4. Wall LL, Brown D. The high cost of free lunch. Obstet Gynecol 2007;110:169-73.

5. Chressanthis GA, Sfekas A, Khedkar P, et al. Determinants of pharmaceutical sales representative access limits to physicians. J Med Market 2014;14:220-43.

6. International, K. Rising costs of litigation in pharmaceutical industry. Issues Monitor-Pharmaceuticals 2011;9:1-3.

7. MedAdNews. Table insert on the top 50 pharma companies. Data provided by Cegedim Strategic Data 2010.

8. Mack J. Pharma promotional spending in 2013. Pharma marketing news. 2014;13.

9. De Ferrari A, Gentille C, Davalos L, et al. Attitudes and relationship between physicians and the pharmaceutical industry in a public general hospital in Lima, Peru. PLoS One 2014;9:e100114.

10. Hodges B. Interactions with the pharmaceutical industry: experiences and attitudes of psychiatry residents, interns and clerks. CMAJ: Canadian Medial Association Journal, 1995;153:553.

11. Riese F, Guloksuz S, Roventa C, et al. Pharmaceutical industry interactions of psychiatric trainees from 20 European countries. Eur Psychiatry 2015;30:284-90.

12. Lee $D$, Begley CE. Physician report of industry gifts and quality of care. Health Care Manage Rev 2016;41:275-83.

13. Montastruc F, Moulis G, Palmaro A, et al. Interactions between medical residents and drug companies: a national survey after the Mediator ${ }^{\circledR}$ affair. PLoS One 2014;9:e104828.

14. Fugh-Berman A, Ahari S. Following the script: how drug reps make friends and influence doctors. PLoS Med 2007;4:e150. 
15. Kesselheim AS, Mello MM, Studdert DM. Strategies and practices in off-label marketing of pharmaceuticals: a retrospective analysis of whistleblower complaints. PLoS Med 2011;8:e1000431.

16. Mulinari S. Unhealthy marketing of pharmaceutical products: An international public health concern. J Public Health Policy 2016;37:149-59.

17. Othman N, Vitry Al, Roughead EE, et al. Medicines information provided by pharmaceutical representatives: a comparative study in Australia and Malaysia. BMC Public Health 2010;10:743.

18. Ziegler MG. The Accuracy of Drug Information From Pharmaceutical Sales Representatives. JAMA: The Journal of the American Medical Association, 1995;273:1296.

19. Alosaimi FD AKA, Qadi M, Albahlal A, et al. Physicians' attitudes towards interaction with the pharmaceutical industry/Attitudes des médecins par rapport á l'interaction avec l'industrie pharmaceutique. East Mediterr Health J 2014;20:812.

20. Andaleeb SS, Tallman RF. Physician attitudes toward pharmaceutical sales representatives. Health Care Manage Rev 1995;20:68-76.

21. Lieb K, Brandtönies S. A survey of german physicians in private practice about contacts with pharmaceutical sales representatives. Dtsch Arztebl Int 2010:107:392-8.

22. Lieb K, Scheurich A. Contact between doctors and the pharmaceutical industry, their perceptions, and the effects on prescribing habits. PLoS One 2014;9:e110130.

23. Francer J, Izquierdo JZ, Music T, et al. Ethical pharmaceutical promotion and communications worldwide: codes and regulations. Philos Ethics Humanit Mede, 2014;9:7.

24. Canada., C.o.f.p.o.C.R.c.o.p.a.s.o. Guide tot enhancing referrals and consultations between physicians. College of Family Physicians of Canada 2009.

25. Grande D. Limiting the influence of pharmaceutical industry gifts on physicians: self-regulation or government intervention? J Gen Intern Med 2010;25:79-83.

26. Brennan TA, Rothman DJ, Blank L, et al. Health Industry Practices That Create Conflicts of Interest. JAMA 2006;295:429.

27. Spurling GK, Mansfield PR, Montgomery BD, et al. Information from pharmaceutical companies and the quality, quantity, and cost of physicians' prescribing: a systematic review. PLoS Med 2010;7:e1000352.

28. Lexchin J. Interactions between physicians and the pharmaceutical industry: what does the literature say? CMAJ: Canadian Medial Association Journal, 1993:14;1407-7.

29. Wazana A, Granich A, Primeau F, et al. Using the literature in developing McGill's guidelines for interactions between residents and the pharmaceutical industry. Acad Med 2004;79:1033-40.

30. Guyatt G, Oxman AD, Akl EA, et al. GRADE guidelines: 1 . Introduction-GRADE evidence profiles and summary of findings tables. J Clin Epidemiol 2011;64:383-94.

31. Thomson AN, Craig BJ, Barham PM. Attitudes of general practitioners in New Zealand to pharmaceutical representatives. $\mathrm{BrJ}$ Gen Pract 1994:44:220-3.

32. Kamal S, Holmberg C, Russell J, et al. Perceptions and Attitudes of Egyptian Health Professionals and Policy-Makers towards Pharmaceutical Sales Representatives and Other Promotional Activities. PLoS One 2015;10:e0140457.

33. Gibbons RV, Landry FJ, Blouch DL, et al. A comparison of physicians' and patients' attitudes toward pharmaceutical industry gifts. J Gen Intern Med 1998;13:151-4.

34 Scheffer MC. Interaction between pharmaceutical companies and physicians who prescribe antiretroviral drugs for treating AIDS. Sao Paulo Med J 2014;132:55-60.

35 Brett AS, Burr W, Moloo J. Are Gifts From Pharmaceutical Companies Ethically Problematic? Arch Intern Med 2003;163:2213.

36 Gupta SK, Nayak RP, Sivaranjani R. A study on the interactions of doctors with medical representatives of pharmaceutical companies in a Tertiary Care Teaching Hospital of South India. J Pharm Bioallied Sci 2016;8:47.

37 Morgan MA, Dana J, Loewenstein G, et al. Interactions of doctors with the pharmaceutical industry. J Med Ethics 2006;32:559-63.

38 Caudill TS, Johnson MS, Rich EC, et al. Physicians, pharmaceutical sales representatives, and the cost of prescribing. Arch Fam Med 1996;5:201-6.

39 Reeder M, Dougherty J, White LJ. Pharmaceutical representatives and emergency medicine residents: a national survey. Ann Emerg Med 1993;22:1593-6.

40 Lichstein PR, Turner RC, O'Brien K. Impact of pharmaceutical company representatives on internal medicine residency programs. A survey of residency program directors. Arch Intern Med 1992;152:1009-13.
41 Brotzman GL, Mark DH. Policies regulating the activities of pharmaceutical representatives in residency programs. J Fam Pract 1992;34:54-8.

42 Alssageer MA, Kowalski SR. A survey of pharmaceutical company representative interactions with doctors in Libya. Libyan J Med 2012;7:18556.

43 Lieb K, Koch C. Medical students' attitudes to and contact with the pharmaceutical industry: a survey at eight German university hospitals. Dtsch Arztebl Int 2013;110:584-90.

44 Brown SR, Evans DV, Fugh-Berman A. Pharmaceutical industry interactions in family medicine residencies decreased between 2008 and 2013: a CERA study. Fam Med 2015;47:279-82.

45 Rahman MH, Agarwal S, Tuddenham S, et al. What do they do? Interactions between village doctors and medical representatives in Chakaria, Bangladesh. Int Health 2015;7:266-71.

46 Klemenc-Ketis Z, Kersnik J. Which pharmaceutical sales representatives' features do slovenian family physicians value? Acta Inform Med 2013;21:257.

47 Hurley MP, Stafford RS, Lane AT. Characterizing the relationship between free drug samples and prescription patterns for acne vulgaris and rosacea. JAMA Dermatol 2014;150:487.

48 Makowska M. Interactions between doctors and pharmaceutical sales representatives in a former communist country. The ethical issues. Camb Q Healthc Ethics 2014;23:349-55.

49 Siddiqui UT, Shakoor A, Kiani S, et al. Attitudes of medical students towards incentives offered by pharmaceutical companies perspective from a developing nation - a cross-sectional study. BMC Med Ethics 2014;15:36.

50 Workneh BD, Gebrehiwot MG, Bayo TA, et al. Influence of Medical Representatives on Prescribing Practices in Mekelle, Northern Ethiopia. PLoS One 2016;11:e0156795.

51 Khan N, Abbas Naqvi A, Ahmad R, et al. Perceptions and Attitudes of Medical Sales Representatives (MSRs) and Prescribers Regarding Pharmaceutical Sales Promotion and Prescribing Practices in Pakistan. J Young Pharm 2016;8:244-50.

52 DeJong C, Aguilar T, Tseng CW, et al. Pharmaceutical IndustrySponsored Meals and Physician Prescribing Patterns for Medicare Beneficiaries. JAMA Intern Med 2016:176:1114.

53 Yeh JS, Franklin JM, Avorn J, et al. Association of Industry Payments to Physicians With the Prescribing of Brand-name Statins in Massachusetts. JAMA Intern Med 2016;176:763.

54 Yeh JS, Austad KE, Franklin JM, et al. Association of medical students' reports of interactions with the pharmaceutical and medical device industries and medical school policies and characteristics: a cross-sectional study. PLoS Med 2014;11:e1001743.

55 Parikh K, Fleischman W, Agrawal S. Industry relationships with pediatricians: Findings from the open payments sunshine act. Pediatrics 2016:137:e20154440.

56 Spingarn RW, Berlin JA, Strom BL. When pharmaceutical manufacturers' employees present grand rounds. what do residents remember?Acad Med 1996;71:86-8.

57 Orlowski JP, Wateska L. The effects of pharmaceutical firm enticements on physician prescribing patterns. There's no such thing as a free lunch. Chest 1992;102:270-3.

58 Zaki NM. Pharmacists' and physicians' perception and exposure to drug promotion: A Saudi study. Saudi Pharm J 2014;22:528-36.

59 Randall ML, Rosenbaum JR, Rohrbaugh RM, et al. Attitudes and behaviors of psychiatry residents toward pharmaceutical representatives before and after an educational intervention. Acad Psychiatry 2005;29:33-9.

60 Esmaily HM, Silver I, Shiva S, et al. Can rational prescribing be improved by an outcome-based educational approach? A randomized trial completed in Iran. $J$ Contin Educ Health Prof 2010;30:11-18.

61 Chren MM, Landefeld CS. Physicians' behavior and their interactions with drug companies. A controlled study of physicians who requested additions to a hospital drug formulary. JAMA 1994;271:684.

62 Zipkin DA, Steinman MA. Interactions between pharmaceutical representatives and doctors in training. A thematic review. J Gen Intern Med 2005;20:777-86.

63 McMurray RJ. Gifts to Physicians From Industry. JAMA: The Journal of the American Medical Association, 1991;265:501.

64 Lotfi T, Morsi RZ, Rajabbik MH, et al. Knowledge, beliefs and attitudes of physicians in low and middle-income countries regarding interacting with pharmaceutical companies: a systematic review. BMC Health Serv Res 2016;16:57.

65 Fischer MA, Keough ME, Baril JL, et al. Prescribers and pharmaceutical representatives: why are we still meeting? J Gen Intern Med 2009;24:795-801. 
66 Chimonas S, Brennan TA, Rothman DJ. Physicians and drug representatives: exploring the dynamics of the relationship. J Gen Intern Med 2007;22:184-90.

67 Saito S, Mukohara K, Bito S. Japanese practicing physicians' relationships with pharmaceutical representatives: a national survey. PLoS One 2010;5:e12193.

68 Lurie N, Rich EC, Simpson DE, et al. Pharmaceutical representatives in academic medical centers. J Gen Intern Med 1990;5:240-3.

69 Bowman MA, Pearle DL. Changes in drug prescribing patterns related to commercial company funding of continuing medical education. J Contin Educ Health Prof 1988;8:13-20.

70 Grundy Q, Bero L, Malone R. Interactions between nonphysician clinicians and industry: a systematic review. PLoS Med 20132013;10:e1001561;10:e1001561.

71 Dixon D, Takhar J, Macnab J, et al. Controlling quality in CME/ CPD by measuring and illuminating bias. $J$ Contin Educ Health Prof 2011;31:109-16.

72. Steinbrook R. Industry Payments to Physicians and Prescribing of Brand-name Drugs. JAMA Intern Med 2016;176:1123.

73 Larkin I, Ang D, Avorn J, et al. Restrictions on pharmaceutical detailing reduced off-label prescribing of antidepressants and antipsychotics in children. Health Aff 2014;33:1014-23.

74 Chressanthis GA, Khedkar P, Jain N, et al. Can access limits on sales representatives to physicians affect clinical prescription decisions? A study of recent events with diabetes and lipid drugs. J Clin Hypertens 2012;14:435-46.
75. Silverman E. Everything you need to know about the Sunshine Act. BMJ 2013;347:f4704.

76. Shalowitz DI, Spillman MA, Morgan MA. Interactions with industry under the Sunshine Act: an example from gynecologic oncology. Am J Obstet Gynecol 2016;214:703-7.

77. Norris P HA, Lexchin J, et al. Drug promotion-what we know, what we have yet to learn-reviews of materials in the WHO/HAl database on drug promotion. EDM Research Series 2005.

78. Carroll AE, Vreeman RC, Buddenbaum J, et al. To what extent do educational interventions impact medical trainees' attitudes and behaviors regarding industry-trainee and industry-physician relationships? Pediatrics 2007;120:e1528-35.

79. Birkhahn RH, Jauch E, Kramer DA, et al. A review of the federal guidelines that inform and influence relationships between physicians and industry. Acad Emerg Med 2009;16:776-81.

80. Sergeant MD HP, Godwin M, Walker DM, et al; Interactions with the pharmaceutical industry: a survey of family medicine residents in Ontario. CMAJ: Canadian Medial Association Journal, 1996;155:1243.

81. T Montague B, Fortin VI AH, Rosenbaum J. A systematic review of curricula on relationships between residents and the pharmaceutical industry. Med Educ 2008;42:301-8.

82. R. P., Guidelines for faculity involvement in commercially supported continuing medical-education. Acad Med 1992.

83. Greenland P. Time for the Medical Profession to Act. Arch Intern Med 2009;169:829. 